\title{
Influence of Non-Uniform Temperature Distribution of the Mold on Solidification Behavior in Large-Size Steel Ingots
}

\author{
Chunping Zhang ${ }^{1}$, Abdelhalim Loucif ${ }^{1}$, Rami Tremblay ${ }^{2}$, Mohammad Jahazi $^{1}$ \\ ${ }^{1}$ École de Technologie Supérieure, Département de Génie Mécanique \\ 1100, Rue Notre-Dame Ouest Montréal, QC, H3C 1K3, Canada \\ Phone: 001(514)396-8800/7868 \\ Email: chunping.zhang.1@ens.etsmtl.ca, abdelhalim.loucif.01@gmail.com, Mohammad.Jahazi@etsmtl.ca \\ ${ }^{2}$ Finkl Steel-Sorel \\ 100 McCarthy, Saint-Joseph-de-Sorel, QC, J3R 3M8, Canada \\ Phone: 001(450)746-4082 \\ E-mails: rtremblay@finkl.com
}

Keywords: Large size steel ingot, Non-uniform mold temperature condition, Temperature field, Solidification speed,
Verification of model

\section{INTRODUCTION}

Large size steel ingots made of high strength steels suffer from the occurrence of chemical heterogeneities, so-call macrosegregation, which result in non-uniform microstructures and mechanical properties. Therefore, their extent and severity need to be controlled. The ingots are often cast inside pits close to a wall or other ingots due to space limitation. These spatial constraints could result in non-uniform-temperature distribution through the diameter and along the height of the mold. Such non-uniformities may induce different solidification patterns, thereby affecting macrosegregation severity and extent in the cast ingots. However, the effect of different casting spatial configurations on the solidification properties is still not clear and needs to be quantified [1-4].

In the present work, the influence of initial temperature distribution pattern on solidification behavior of a $40 \mathrm{MT}$ steel ingot was numerically studied. The finite element modeling of the bottom pouring, filling and solidification process of a 40MT (metric ton) steel ingot was realized using the Finite Element Code Thercast ${ }^{\mathbb{R}}$ and a pseudo-2D model [5]. Two cases were studied: one was with uniform initial thermal condition on the mold, and the other with different initial temperature levels on the opposite sides of the mold. The temperature field and solidification rate were compared between the two case studies. Material properties were obtained from the literature and authors' experimental work [6]. The thermal predictions were compared with the thermal measurements from the casting experiments. The predicted results are discussed in the framework of heat transfer and solidification mechanisms.

\section{ESTABLISEHMENT OF MODEL}

The pseudo-2D model used in the present study was first established using the commercial CAD software CATIA ${ }^{\circledR}$ [7] and then transferred into finite element $(\mathrm{FE})$ code Thercast $^{\circledR}$ [5]. It was composed of an ingot $250 \mathrm{~cm}$ in height and $150 \mathrm{~cm}$ in width in a big-end-up cast iron mold, as displayed in Figure 1a. The mold was hot-topped $70 \mathrm{~cm}$ in height with insulating refractory tiles lined inside. A layer of insulating exothermic refractory board was over laid on the melt top. 3D linear tetrahedral elements were used for the spatial discretization of the part and mold components, as shown in Figure 1b. An average grid size of $35 \mathrm{~mm}$ was selected based on a mesh size optimization analysis. The thickness of the model was discretized by 2 elements. The numbers of nodes and elements in the steel part were 19662 and 86867, while they were 57243 and 250857 for the pseudo-2D casting system.

Two cases for the initial mold temperature condition were simulated, as seen in Figure 2. The first one, named MS, was with the mold at the same initial temperatures $\left(50^{\circ} \mathrm{C}\right)$ for both sides. The other was MD, with the mold at different initial temperatures for the left $\left(50^{\circ} \mathrm{C}\right)$ and right sides $\left(150^{\circ} \mathrm{C}\right)$. The material was a medium carbon steel with the nominal chemical 
composition listed in Table 1. For both cases, the liquid steel was bottom poured into the mold at $1570^{\circ} \mathrm{C}$ (with a superheat of $75^{\circ} \mathrm{C}$ ) with a filling time of $30 \mathrm{~min}$. The calculations were stopped when the entire casting came to complete solidification (i.e. around $1400^{\circ} \mathrm{C}$ ). For both MS and MD, five sensors (SENs 1-5) were installed in specified positions, at $2.5 \mathrm{~cm}$ from the mold outside surface, as presented in Figure 1a, to monitor their temperature changes throughout the casting process.

Volume-averaged solid-liquid two-phase thermic models, as reported detailed in [5], were used for the simulation of mold filling and solidification. An Arbitrary Lagrangian-Eulerian (ALE) formulation was used for managing the time-dependent evolution of metal mass in the mold during the filling phase. Pure heat conduction was assumed as the only heat dissipation manner. Thermal convection, solid and mold deformation, elemental distribution and sedimentation of equiaxed grains were not taken into account, either because they are not considered in the FE code or to reduce the calculation time. The detailed derivation of associated auxiliary equations can be found in reference [5]. The determination of relevant material parameters is based on the data provided in [6].

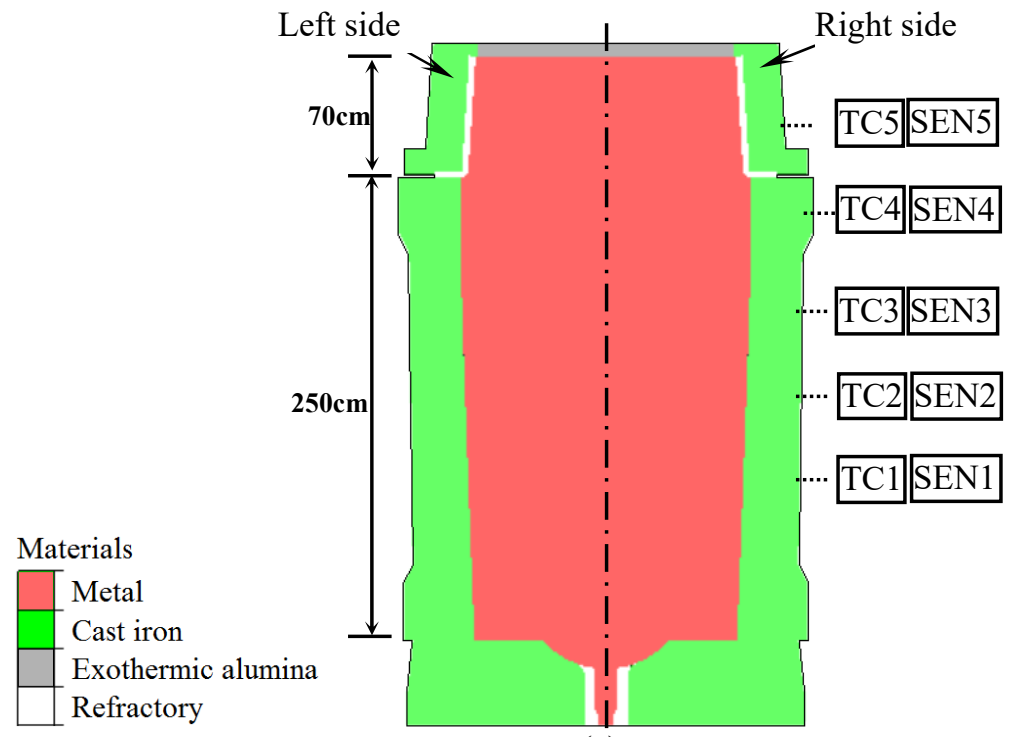

(a)

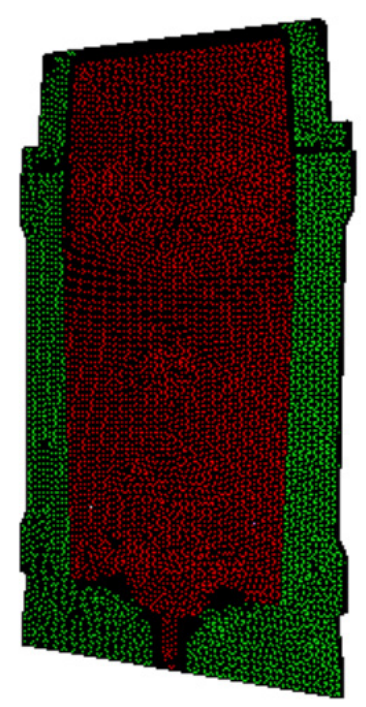

(b)

Figure 1. Peudo-2D Finite Element model: (a) main parts and corresponding materials with sensors (SENs) placed in the same positions as the thermocouples (TCs), (b) mesh distribution.

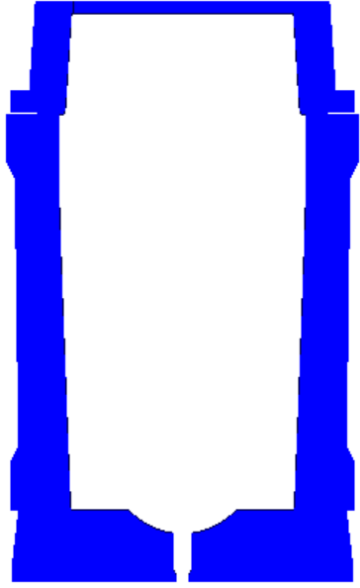

(a)

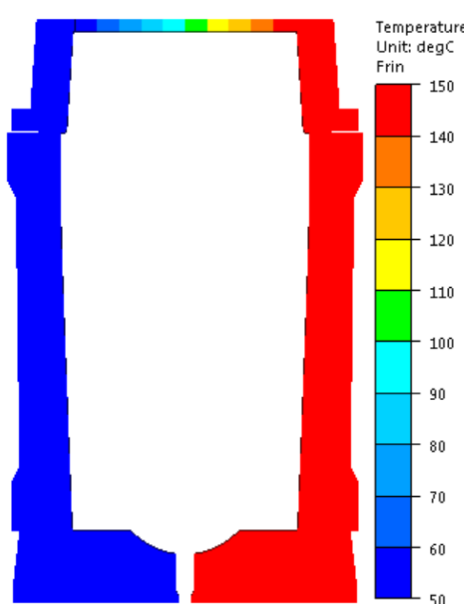

(b)

Figure 2. Initial mold temperature conditions of the two case studies: (a) MS with the same initial temperature on both sides of the mold, (b) MD with different temperatures on left and right sides of the mold.

Table 1. Nominal chemical composition of the studied steel (wt.\%).

\begin{tabular}{ccccccccc}
\hline $\mathrm{C}$ & $\mathrm{Si}$ & $\mathrm{Mn}$ & $\mathrm{S}$ & $\mathrm{Cr}$ & $\mathrm{Mo}$ & $\mathrm{P}$ & $\mathrm{Ni}$ & $\mathrm{Fe}$ \\
\hline 0.36 & 0.4 & 0.85 & 0.0023 & 1.82 & 0.45 & 0.01 & 0.16 & balance \\
\hline
\end{tabular}




\section{EXPERIMENTAL PROCESS}

To verify the established model and examine the predictions, two cylindrical ingots (IngotS and IngotD), with $250 \mathrm{~cm}$ in height and $150 \mathrm{~cm}$ in mean diameter, were cast experimentally, in the same material and in the casting system identical to that presented in Figure 1a. IngotS was fabricated under the same casting condition as MS (i.e. at $1570^{\circ} \mathrm{C}$, with a filling time of $30 \mathrm{~min}$, and initial uniform mold temperature of $50^{\circ} \mathrm{C}$ ), while IngotD was corresponding to that for MD. In order to create the non-uniform initial temperature condition for IngotD, two neighbouring ingots, with the layout illustrated in Figure 3 , were cast in turn. Ingots Left and Right began their casting processes 6 and 3 hours, respectively, before the beginning of the pouring operation for IngotD. Both IngotD and its neighbours were cast at $1576^{\circ} \mathrm{C}$ with a filling time of $34 \mathrm{~min}$.

For IngotS and IngotD, the temperature variations on the outside surface of the mold were monitored throughout the casting process using Chromel-Alumel thermocouples (TCs, type K) located in the same positions as SENs, as presented in Figure 1a. For IngotS, all 5 TCs were installed on the right side of mold surface. For IngotD, only TCs 1-4 were set up on the mold left and right outside surfaces, respectively. For the two experimental ingots, each thermocouple was cemented into holes drilled $2.5 \mathrm{~cm}$ into the mold from the exterior surface. Temperature measurements from each thermocouple were made every 90 seconds from the start of the steel pouring until the ingot was removed from the mold.

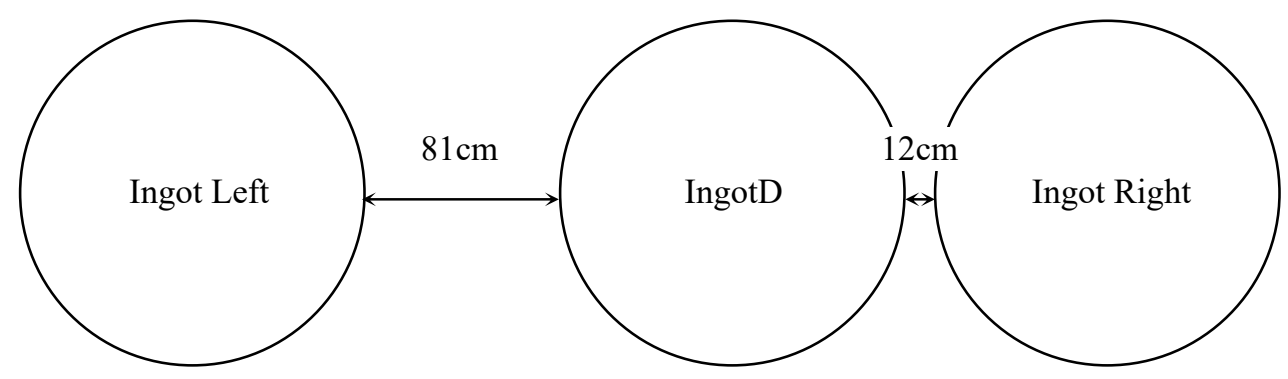

Figure 3. Layout of IngotD and its neighbors.

\section{RESULTS AND DISCUSSION}

\section{Temperature field and solidification speed}

Temperature fields for MS (with $50^{\circ} \mathrm{C}$ as the initial uniform temperature of the mold) at times of 0.25 ( $50 \%$ filling), $0.5 \mathrm{~h}$ (end of filling), together with 1.5h, 2.5h, 5.5h, 10.5h and 15.5h after pouring are shown in Figure 4. The interface between the ingot and the mold was marked artificially with dashed lines. It can be seen that before the end of the filling stage, in the casting, a slight horizontal temperature gradient is present close to the mold chill wall and a vertical one next to the mold base (Figure 4a). The height of the thermal gradient kept pace with the metal advance front in the vertical direction. This indicates the immediate dissipation of the superheat due to heat conduction from the cold mold wall. The heat from the steel melt was conducted to the mold wall, inducing a weak thermal gradient in the mold interior layer in contact with the ingot skin. When the filling operation was completed, Figure $4 \mathrm{~b}$, the horizontal and vertical temperature variation fields became larger, in both the casting and the mold, owing to the increased accumulation of heat from the large liquid bulk. No large temperature variation occurred in the hot-top shell, as compared with the skin region of the ingot body. This delay in heat loss in the hot-top could be due to the effective protection provided by the nonconductive refractory board.

As solidification proceeded, the horizontal isotherms at the bottom became inclined and the spacing between adjacent isotherms widened, as seen in Figures 4c-g. This indicates the progressive development of the solidification, upward from the ingot bottom and inward from the cold mold wall, due to heat conduction. It should be noted that the temperature field on the left half of the casting and the mold was always a symmetric version of the right pattern, through the whole casting process from its start to its completion. The above evolution of temperature patterns in MS is similar to those reported by Im et al. for pure heat conduction analysis [8].

However, in $\mathrm{MD}$ (with $50^{\circ} \mathrm{C}$ and $150^{\circ} \mathrm{C}$ as the initial temperatures for the left and right sides of the mold), different features in the temperature field during the casting process was observed, as seen in Figure 5. An asymmetry in the temperature field in the mold was developed from the start of the pouring process. When the mold cavity was half filled, as seen in Figure 5a, a $100^{\circ} \mathrm{C}$ higher initial temperature on the mold right gave rise to a heat penetration almost through the entire thickness of the mold. In contrast, on the left side of the mold, the thermal gradient was quite small and a large area of the mold was thermally unaffected. Particularly, the temperature on the right interior surface of the mold appeared higher. The region with larger thermal gradient and higher temperature value on the right side of MD were maintained up to the completion of the filling operation, as seen in Figure 5b. Then, the tendency decayed with time and came to disappear after $5 \mathrm{~h}$, as observed in 
Figures $5 \mathrm{c}$-g. However, the impact of the initial non-uniform mold temperature on the temperature field in the casting is not that remarkable.

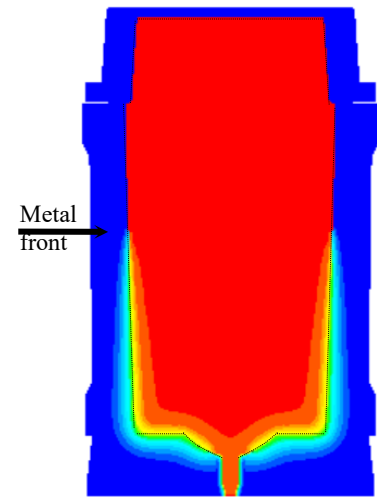

(a)

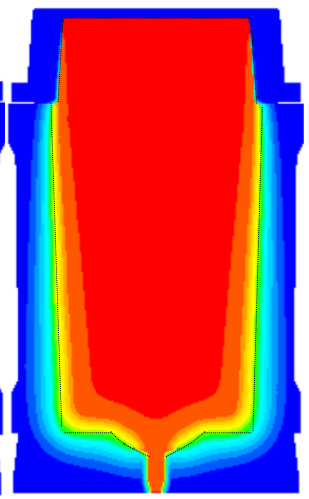

(b)

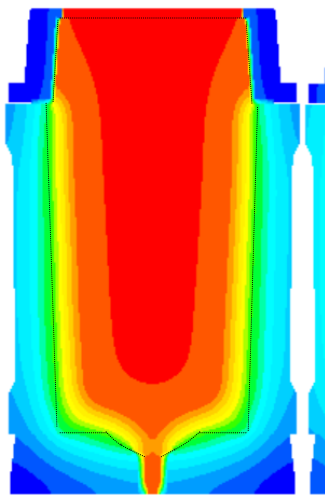

(c)

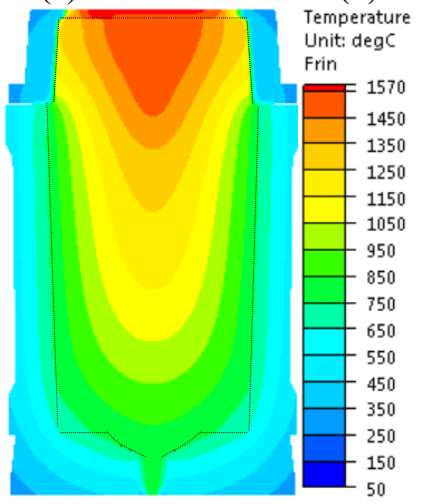

(g) (d)

Temperature Unit: deg Frin

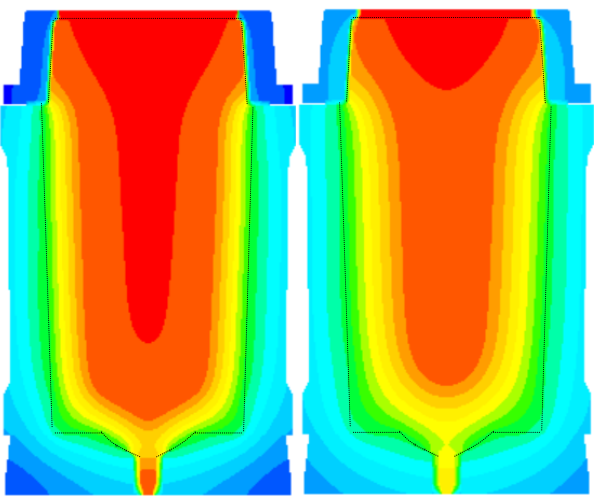

(e)

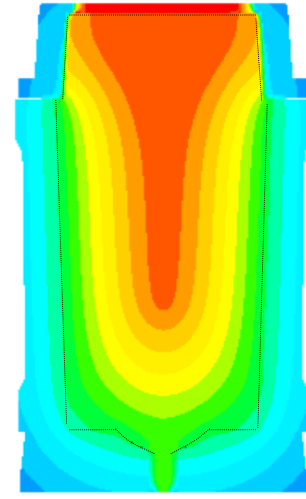

(f)

Figure 4. Temperature pattern in the casting process for MS at times of (a) $0.25 \mathrm{~h}(50 \%$ filling), (b) $0.5 \mathrm{~h}$ (end of filling), (c) $1.5 \mathrm{~h}$, (d) $2.5 \mathrm{~h}(\mathrm{e}) 5.5 \mathrm{~h}$, (f) $10.5 \mathrm{~h}$ and (g) $15.5 \mathrm{~h}$ after pouring.

In order to further compare the temperature fields in the casting between MS and MD cases, the temperature profiles of 6 specific points were analyzed. As illustrated in the upper right corner of Figure 6, points 1-4 were located in the skin and center of the mid-height sections of the hot-top and ingot body, respectively, to study the evolution of the radial temperature difference in the two parts. Points 5 and 6 were set at the top and bottom of the casting so that the vertical thermal change along the axis of the whole casting could be examined. For MD, the points on the skin of the casting were selected on both left and right sides, and named 1Left, 1Right and 3Left and 3Right, corresponding to their respective sides. The same labeling rule was applied for all the following analyses unless stated otherwise.

In the hot-top, as given in Figure 6a, the hotter right side of the mold in MD generated higher temperature on the hot-top periphery (point 1Right_MD), while the temperature profiles on the hot-top left skin (point 1Left_MD) and its center (point 2) presented by MD were similar to those of MS in the corresponding locations (points 1_MS and 2_MS). This finding indicates that a smaller temperature gradient was induced in the half of the hot-top with higher initial thermal condition. Quantitative examinations of the radial temperature difference in the mid-height of the hot-top were done for MS, left side of MD and right side of MD. Their temperature gradient reached $0.0228^{\circ} \mathrm{C} / \mathrm{cm}, 0.0228^{\circ} \mathrm{C} / \mathrm{cm}, 0.0215^{\circ} \mathrm{C} / \mathrm{cm}$ at $5 \mathrm{~h}$, respectively, and then reached $0.0291,0.0294,0.028^{\circ} \mathrm{C} / \mathrm{cm}$ at $10 \mathrm{~h}$, and further $0.0394,0.0394,0.0384^{\circ} \mathrm{C} / \mathrm{cm}$ at $15 \mathrm{~h}$. From this, it can be seen that the different temperature gradients between two halves of the hot-top in MD remain all along the cooling process, and tend to weaken with the solidification proceeding.

In the ingot body, as given in Figure 6b, a smaller temperature gradient in the right half in MD was also obtained (the distance between the points 3Right_MD and 4_MD was smaller at any given moment) until after 8h. This corresponds to the time when solidification occurred almost above the mid-height. For MS, left half of MD and right half of MD, on the section at the mid-height of the ingot body, the radial temperature gradients were $0.0928,0.0929,0.0906^{\circ} \mathrm{C} / \mathrm{cm}$ at $5 \mathrm{~h}$. But at $10 \mathrm{~h}$, they reached $0.0935,0.0937,0.0937^{\circ} \mathrm{C} / \mathrm{cm}$, proving the disappearance of the thermal inconsistency between the two halves in MD. 
Comparative analysis of the temperatures at the top center of the casting (point 5) in Figure 6c revealed no significant difference between MS and MD. However, at the last solidification stage (after 22h), MD displayed a slower cooling rate. The temperatures at the bottom base (point 6) in MD showed slightly higher values, indicating decreased thermal gradient along the centerline of the ingot.

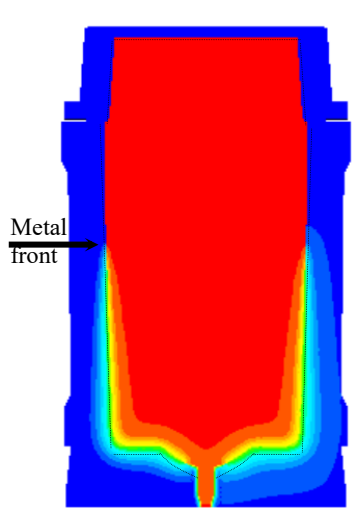

(a)

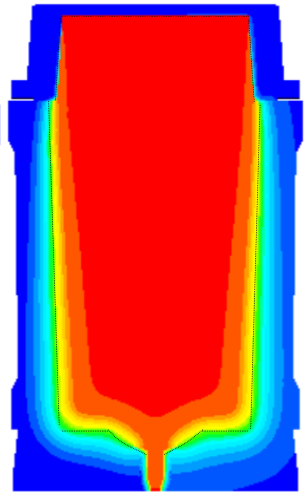

(b)

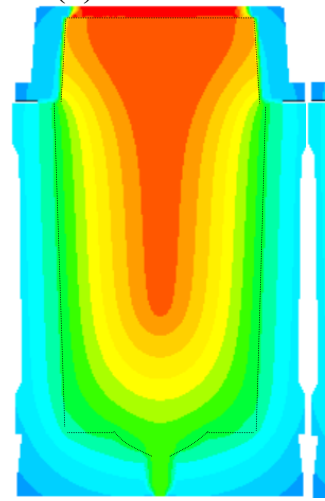

(f)

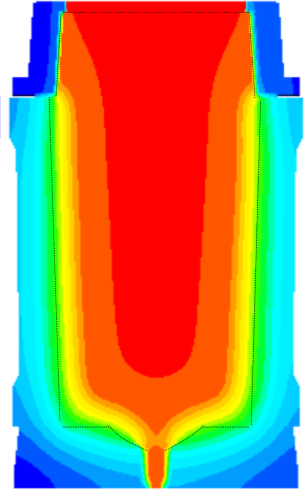

(c)

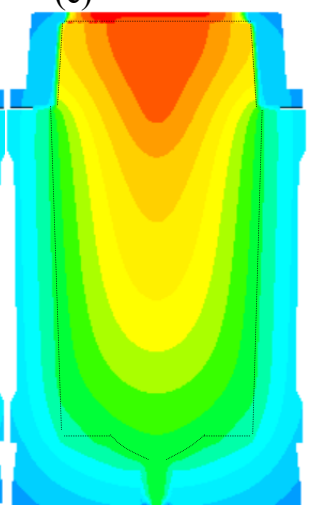

(g)

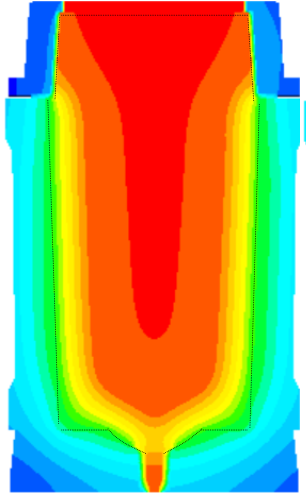

(d) Temperature Unit: degC Frin

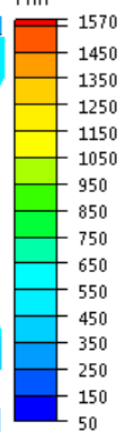

Figure 5. Temperature pattern in the casting process for MD at times of (a) $0.25 \mathrm{~h}(50 \%$ filling), (b) $0.5 \mathrm{~h}$ (end of filling), (c) $1.5 \mathrm{~h},(\mathrm{~d}) 2.5 \mathrm{~h}(\mathrm{e}) 5.5 \mathrm{~h}$, (f) $10.5 \mathrm{~h}$ and (g) $15.5 \mathrm{~h}$ after pouring.

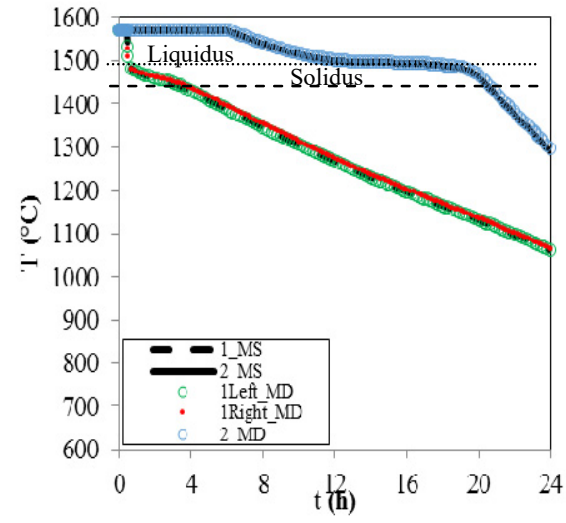

(a)

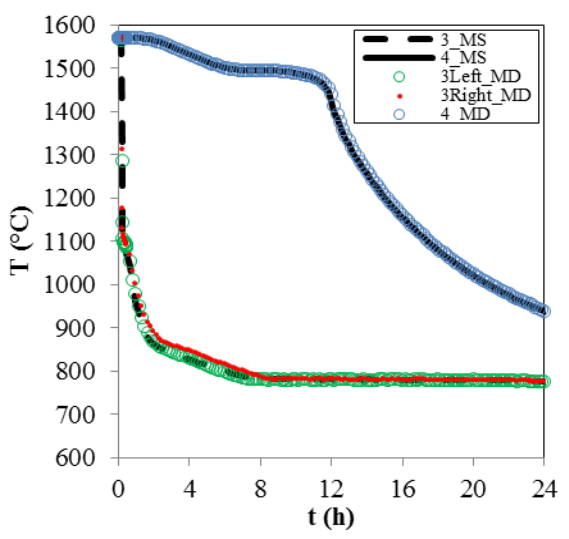

(b)

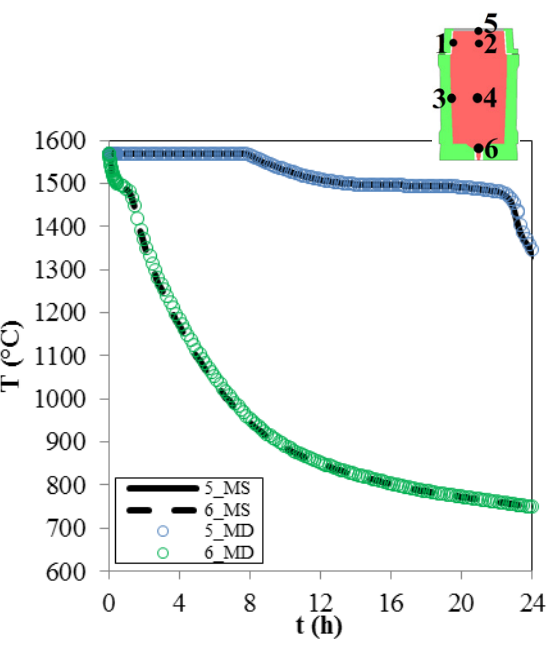

(c)

Figure 6. Evolution of the temperature profiles in MS and MD during the casting process: (a) on points 1 and 2 in mid-height of hot-top, (b) on points 3 and 4 in mid-height section of ingot body, (c) on points 5 and 6 along the casting centerline.

The above-mentioned asymmetry in temperature field in MD resulted in different solidification pace between the left and right halves in the whole casting, as given in Figure 7. In MS, the advance speed of the metal solid front kept always the 
same pace on both halves, as observed in Figures 7a-e. This phenomenon is quite contrary to the lag of the right part behind the left in MD in the first solidification stage, as seen in Figures 7f-j. Such delayed cooling tendency on the right side was more remarkable in the hot-top, the location with longer stay of hot bulk liquid. Examination of the delay along the hottop/ingot body interface section showed that the solid front on MD right was $0.5 \mathrm{~cm}, 1.1 \mathrm{~cm}$ and $2.2 \mathrm{~cm}$, respectively, behind its left side at $5 \mathrm{~h}, 10 \mathrm{~h}$ and $15 \mathrm{~h}$, as plotted in Figure 8. This slower solidification speed during the casting on the side with initially hotter mold is in accordance with the higher right half temperature profiles reflected in Figure 6. Such delayed solidification on one side results in a longer time necessary for the triggering of the solidification and for the completion of solidification process, as predicted by MS and MD in Figure 9.
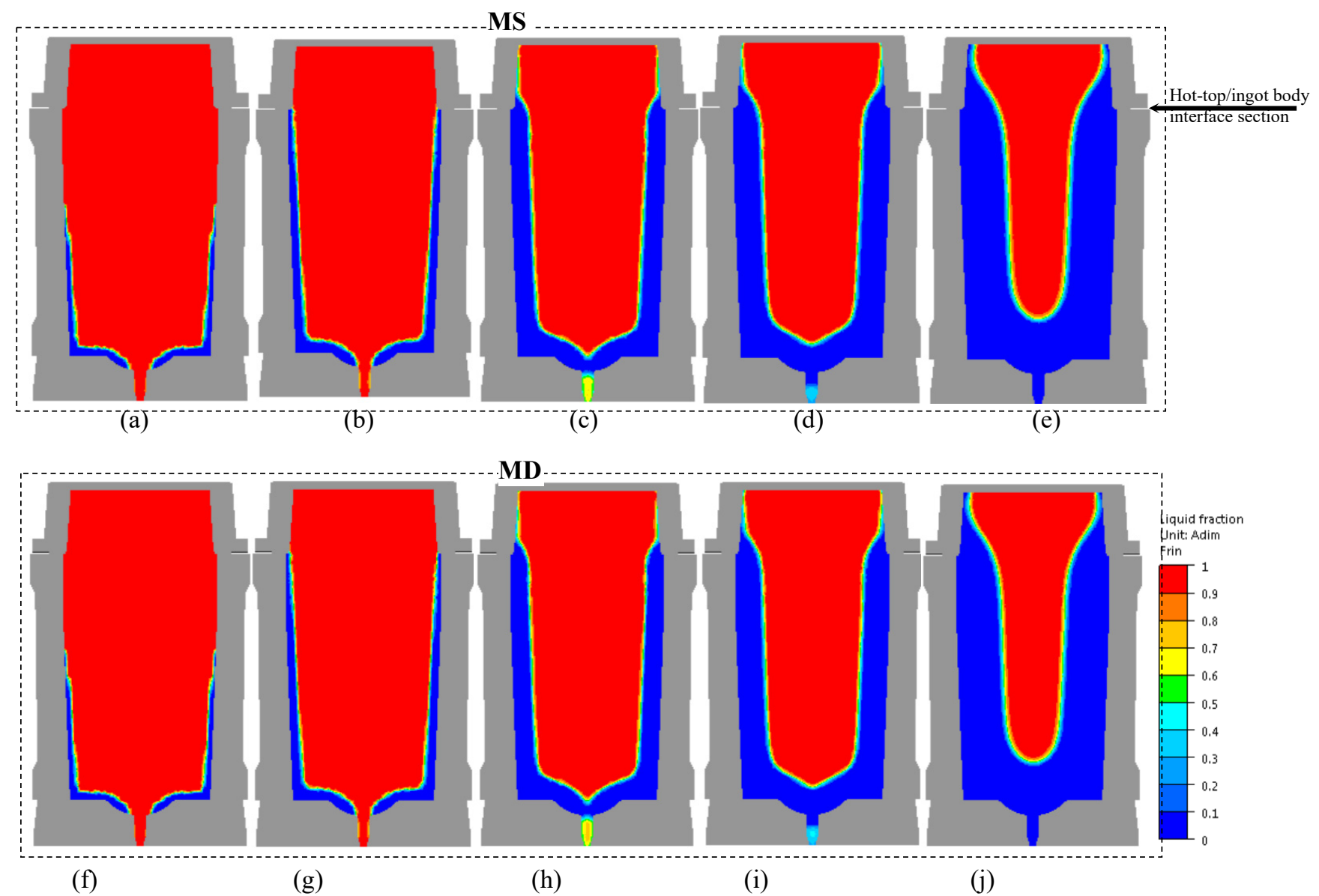

Figure 7. Liquid fraction pattern in the casting process for MS and MD at times of (a, f) $0.25 \mathrm{~h}(50 \%$ filling), (b, g) $0.5 \mathrm{~h}$ (end of filling), (c, h) $1.5 \mathrm{~h},(\mathrm{~d}, \mathrm{i}) 2.5 \mathrm{~h}$, and (e, j) $5 \mathrm{~h}$ after pouring. 


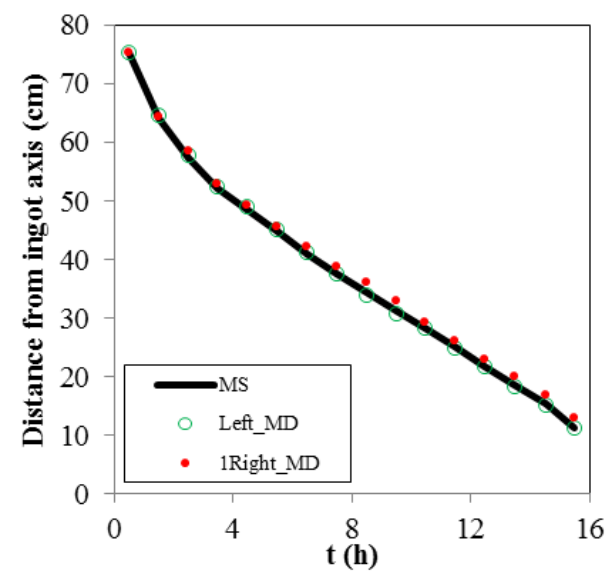

Figure 8. Time-dependent distance of the solid front from the ingot centerline along the hot-top/ingot body for MS, left and right sides of MD.

It has been reported that a lower temperature gradient can prolong the thermal convection time in the mold cavity, and delay the development of solutal convection [9], and thus can significantly affect the distribution of solutes [10]. Lower solidification speed can result in more time available for solutes to transport and increased segregation intensity [4]. Thus, the above-mentioned asymmetry in the temperature distribution through the diameter and along the height of the ingot and in the radial solidification speed in the early stage of solidification can affect the macrosegregation symmetry and severity in the large-sized cast ingots.

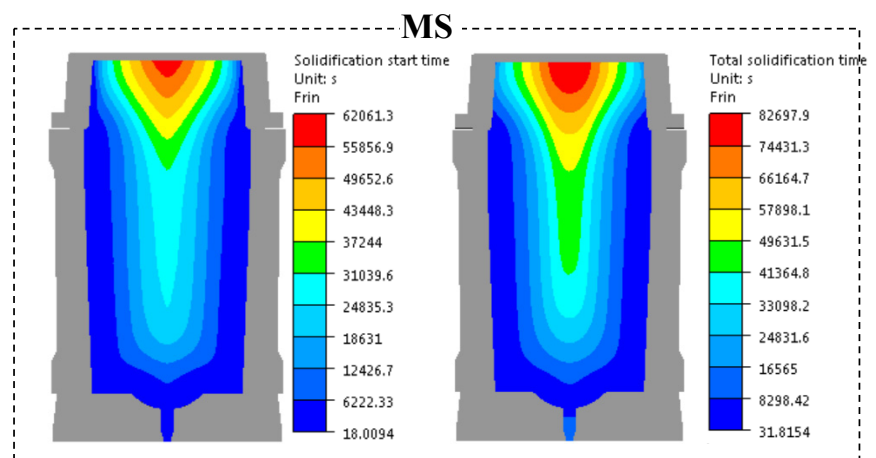

(a)

(b)

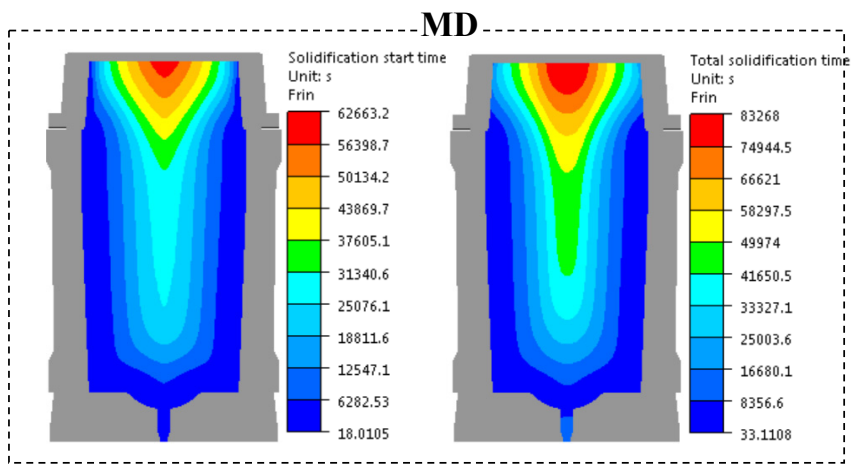

(c) (d)

Figure 9. Solidification time predictions from MS and MD: (a, c) solidification start time, (b, d) total solidification time.

\section{Verification of the model}

For the validation of the thermal predictability of the established model, temperature predictions from the sensors (SENs) for the MS case were compared with thermal readings of thermocouples (TCs) from the experimentally obtained IngotS, in light of their same casting conditions. The thermal sensors were placed at the same characteristic positions as thermocouples, as illustrated in Figure 1a.

According to the experimental measurements from IngotS, as shown in Figure 10a, at first, the temperatures sharply increased one after another, reflecting the successive contact between the melt and mold during pouring. Then, the increasing tendency was slowed down because of the heat loss from the mold wall. Temperatures began to decrease after reaching their individual temperature peaks. Owing to the low conductivity of the insulating tiles inside the hot-top mold, the increasing tendency was slowed and the lowest peak temperature value was recorded by TC5.

When sensor readings of MS were examined, it was found that all the above features were, at large, reproduced. The $20-50^{\circ} \mathrm{C}$ difference in the peak values between the predictions of MS and test results of IngotS could be due to the uncertainty in the exact values of the thermal conductivity of the cast iron mold and the refractory tiles used in the computations. The 3-4h advance in the temperature peak for MS are attributed to the predictive failure of air gap formation, and thus of heat transfer transition from pure conduction to heat radiation. The difference between the spacing of SENs 1-3 and that of TCs 1-3 originates from the shortness of the predictability about the increasing air gap size from the bottom up along the ingot skin. 
The smaller heat loss after $8 \mathrm{~h}$ is probably related to the not taking into account the effect of solid contraction and volume shrinkage, which can help to accelerate the solidification in the latter solidification stage.

The difference in the temperature variation trend between the left and right halves of MD was also reflected on the mold outside surface. As seen in Figure 10b, the temperatures on the side with higher initial mold temperature (right side) increased earlier than the other colder side. Furthermore, their peak values arrived at $40^{\circ} \mathrm{C}$ higher. This difference became smaller with the solidification proceeding, and did not disappear until after as long as $12 \mathrm{~h}$.

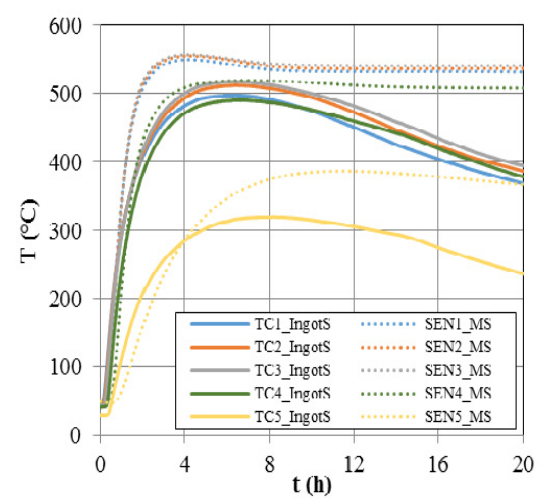

(a)

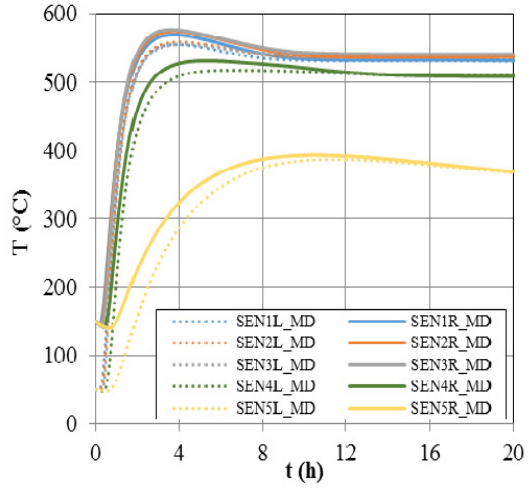

(b)

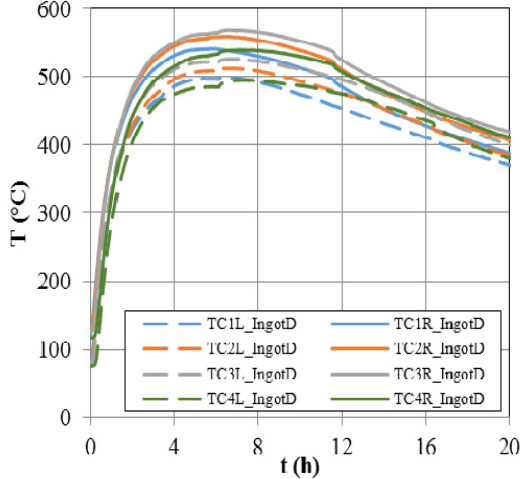

(c)

Figure 10. Time-dependent temperature change on the outside of the mold surface in the casting process: (a) thermal couple readings of the IngotS (TC) and the sensor values of MS (SEN), (b) sensor values from the left side (SENL) and the right side (SENR) of the mold surface of MD, (c) thermal couple readings for the left side (TCL) and the right side (TCR) of the mold surface of IngotD.

As a result of the dissimilarity of the initial temperature conditions between the two opposite mold sides, the temperature difference between two halves predicted by MD was confirmed by experimental results from IngotD, as seen in Figure 10c. Furthermore, the predicted thermal gradients on the two sides appear less severe and last for much shorter time than real industrial production. In the figure, it can be noted that the initial $40^{\circ} \mathrm{C}$ difference between left $\left(80^{\circ} \mathrm{C}\right)$ and right $\left(120^{\circ} \mathrm{C}\right)$ mold skins for IngotD kept constant till after $12 \mathrm{~h}$, and then decreased down to $20^{\circ} \mathrm{C}$ after $20 \mathrm{~h}$. The long-lasting unchanged thermal difference and its longer effective time in the experimental case are probably due to the continuous thermal gain from the radiation from the neighbouring ingots. Therefore, in actual industrial production, the above-discussed asymmetry phenomena in thermal pattern and solidification speed caused by neighboring ingot casting, or non-uniform initial mold temperature, should be taken into consideration.

\section{CONCLUSIONS}

In the present work, the effect of non-uniform initial mold temperature conditions on the solidification behavior of largesized steel ingot was numerically studied. A uniform initial mold temperature case was also simulated for comparison. For both cases, pure heat conduction was considered to be the only heat dissipation manner. It was found that non-uniform initial temperature condition of the mold led to asymmetry in the temperature field, temperature gradient and solidification speed in the casting. This finding is in contrast to the symmetry patterns in the casting of the case with uniform initial mold temperature. In addition, a higher temperature on one side of the mold tends to delay solidification process. This asymmetry and the solidification lag should influence the distribution of alloying elements, given that the development of macrosegregation is significantly influenced by the solidification conditions. The predicted results agreed well with experimental measurements. The results of the present study provide original information about the impact of non-uniform initial temperature distribution of a large-size mold in the ingot cooling process.

\section{ACKNOWLEDGEMENTS}

Finkl Steel-Sorel Co. is greatly appreciated for providing the material. The financial support from the Natural Sciences and Engineering Research Council (NSERC) of Canada in the form of a Collaborative Research and Development Grant (CRDG) under number 470174 is gratefully acknowledged. 


\section{REFERENCES}

1. T. Pikkarainen, V. Vuorenmaa, I. Rentola, M. Leinonen, D. Porter, Effect of Superheat on Macrostructure and Macrosegregation in Continuous Cast Low-alloy Steel Slabs, IOP Conf. Ser. Mater. Sci. Eng. 2016, 117, pp 1-7.

2. A.N. Galkin, N.A. Zyuban, D.V. Rutskii, S.B. Gamanyuk, A.Y. Puzikov, V.V.Firsenko, Effect of Chilling of the Top Part of a Steel Ingot on the Conditions of its Crystallization and the Quality of Forgings Obtained from it. Metallurgist, 2013, 57, pp 199-206.

3. V.S. Dub, A.N. Romashkin, A.N. Mal'ginov, I.A. Ivanov, D.S. Tolstykh, Effect of the Geometry of an Ingot on its Chemical Heterogeneity. Part I. Metallurgist 2014, 57, pp 987-995.

4. C. Zhang, A. Loucif, M. Jahazi, R. Tremblay, L.P. Lapierre, On the Effect of Filling Rate on Positive Macrosegregation Patterns in Large Size Cast Steel Ingots, Appl. Sci., 2018, 8, 1878.

5. THERCAST $8.2^{\circledR}$, Transvalor, S.A., Cedex, France.

6. C. Zhang, D. Shahriari, A. Loucif, H. Melkonyan, M. Jahazi, Influence of Thermomechanical Shrinkage on Macrosegregation during Solidification of a Large-sized High-strength Steel Ingot, Int. J. Adv. Manuf. Technol., 2018, 99, pp 3035-3048.

7. CATIA V5 R20, Avions Marcel Dassault, France.

8. I.T. Im, W.S. Kim, K.S. Lee, A Unified Analysis of Filling and Solidification in Casting with Natural Convection, Int. J. Heat Mass. Tran., 2001, 44, pp 1507-1515.

9. D.R. Liu, X.H. Kang, P.X. Fu, D.Z. Li, Modeling of Macrosegregation in Steel Ingot: Influence of Mold shape and Melt Superheat. Kovove Mater. 2011, 49, 143-153.

10. L. Hachani, B. Saadi, X.D. Wang, A. Nouri, K. Zaidat, Experimental Analysis of the Solidification of Sn-3 wt .\% Pb Alloy under Natural Convection. Intl. J. Heat Mass Transf. 2012, 55, pp 1986-1996. 